\title{
Finite Element Method Analysis of the Stress for Line Pipe with Corrode Groove During Outdoor Storage
}

\author{
Zhuanzhao YANG ${ }^{\dagger}$, Daoxin LIU and Xiaohua ZHANG \\ Northwestern Polytechnical University, Xi'an 710072, China \\ [Manuscript received 22 July 2012, in revised form 31 December 2012] \\ (C) The Chinese Society for Metals and Springer-Verlag Berlin Heidelberg
}

\begin{abstract}
The basic principle of corrode groove on outside of steel pipe during storage was analyzed in this paper, namely the water film on the contacted surface of steel pipe, which gathered from humidity in the air, rain or gel, and the suspended particles in air, and the corrosive composition, such as $\mathrm{SO}_{2}, \mathrm{CO}_{2}, \mathrm{O}_{2}$ and $\mathrm{NaCl}$, in addition to the inhomogeneity of the organization and composition, which lead to the corrosion cell reaction, so that cause the corrosion initial from the contact surface of the between steel pipes, so as to form the corrosion groove.

At the same time, the corrosion groove with depth of $0.125 t$ ( $t$ pipe wall thickness) on the pipe of $\Phi 1016 \mathrm{~mm} \times 21 \mathrm{~mm}$ X70 API SPEC $5 \mathrm{~L}$ was simulated using the FEM (finite element method), and the stress and strain distribution of the defect area near corrosion groove were solved at the inner pressure of $12 \mathrm{MPa}, 10 \mathrm{MPa}, 8 \mathrm{MPa}, 6 \mathrm{MPa}, 4 \mathrm{MPa}$ and $2 \mathrm{MPa}$, respectively, which showed that no matter the pressure values were, the maximum stress and strain were lied at the bottom of corrosion defects groove and were in good linear relationship with the internal pressure increasing from $2 \mathrm{MPa}$ to $6 \mathrm{MPa}$. When the internal pressures were greater than $6 \mathrm{MPa}$, they felled into the nonlinear model and to be yielded or even to be destroyed. In addition, the residual strength and the limit operation pressure of the corrode pipe with the defects groove of $0.125 t$ were calculated or simulated according to the theoretical calculation, the finite element method based on the stress, the finite element method based on strain, DNV-RP-F101, ASME B31G and experimental methods respectively. The results showed that the residual strength and the limit operation pressure of the defective parts solved by the finite element method based on stress were $424 \mathrm{MPa}$, and $15.34 \mathrm{MPa}$, respectively, which was very close to that of experimental method, the residual strength was $410 \mathrm{MPa}$ and the limit operation pressure $14.78 \mathrm{MPa}$. Besides, the results also showed that it was feasible and effective to simulate the residual strength of the structure with corrosion defects using the finite element method.
\end{abstract}

KEY WORDS: Finite element methods (FEM); Storage; Corrode Groove; Stress analysis; von Mises equivalent stress

\section{Introduction}

As the oil and gas resources strategic position was constantly strengthened and attention in the world, and the domestic oil and gas storage and transportation projects were increased year by year, especially the long distance pipeline construction projects, there were lots of line pipe left and long time exposed to

\footnotetext{
† Corresponding author. Ph.D.; Tel: +86 29 88726396; Fax: +8629 88726175; E-mail address: yangzhuanzhao@163.com (Zhuanzhao YANG)
}

DOI: $10.1007 / \mathrm{s} 40195-012-0122-4$ outdoor conditions, some on the station pipeline construction site, some on the pipe manufacturer's yard, because of the design change, time span of the great projects, engineering quantity surplus, transit transport and so on, the exposure time may be 1-2 years or even longer, additionally because of the rain and other natural environmental conditions, some even inventory place close to the coastal area, there were always corrosion groove defects at the contacting outside surface between the adjacent pipe, which lined with the pipe axial (longitudinal direction).

In a survey of domestic great pipeline engineering project, there were about 10000 tons of all kinds of 
steel pipes left after the project completion, and the majority of the pipes were corroded groove defect with different degrees during the outdoor storage. If all of these pipes scrapped, the owner of the project wasted not only a lot of manpower and material resources, but also more iron ore resources. For the defects research methods, there were SINTAP evaluation method risk assessment, and so on. Adib-Ramezani ${ }^{[1]}$ has given a SINTAP assessment and simulation for service pipe under the condition of the corrosion defects. Anghel ${ }^{[2]}$ made risk assessment on pipeline containing active defect corrosion using artificial intelligence method. In addition, there were fault tree analysis method, the Monte Carlo method, probability statistics, the finite element method, full scale blast test method, etc. Ref. [3] comprehensively introduced evaluation method for the common corrosion pipeline volume type defect and its advantages and disadvantages. Summery, the finite element method was widely used in defect simulation calculation.

Meliani et al. ${ }^{[4]}$ simplified the corrosion defects as parabolic section and rectangular section. Rollins et $a l .{ }^{[5]}$ simplified the defect as appearance pastry hemispherical. Meanwhile, Rivas et al. ${ }^{[6]}$ systematically researched about pit measurement and analysis methods by immersed corrosion of steel API 5L $\mathrm{X} 52$ in soil by extreme value method, and Caleyo et al. ${ }^{[7]}$ investigated the probability distributions of external-corrosion pit depth and pit growth rate of underground pipelines using Monte Carlo simulations.

Chiodo and Ruggieri ${ }^{[8]}$ evaluated the pipeline containing axial corrosion defects, which based on stress analysis results. Zhu and Leis ${ }^{[9]}$ put forward and applied the average shear yield criterion. Moustabchir et al. ${ }^{[10]}$ adopted the extensometer to measure the stress-strain state of near the longitudinal half an ellipsoid defect on steel pipe pressured inside and compared the results of FEM simulation and experiments.

At the background of trying to reuse the 10000 tons pipes with groove corrosion during the outdoor storage exposed to the atmosphere, the groove corrosion principle of the storage was analyzed in this paper, to the groove defect model with a depth of $0.125 t$ ( $t$ is the pipe wall thickness) on the pipe of $\Phi 1016$ $\mathrm{mm} \times 21 \mathrm{~mm}$ X70 API SPEC $5 \mathrm{~L}$ and its stress and strain distribution were simulated by the finite element method. The residual strength and the limit operation pressure of the corrode pipes with the groove defects were comparably calculated. So it may provide reference for pipe inspection, project decisionmaking, engineering design and stress analysis.

\section{Principle of Storage Corrode Groove}

The corrode groove defect on outside of steel pipe during storage should belong to the typical carbon steel atmospheric corrosion behavior. The sketch of pipe groove corrosion during storage is shown in the Fig. 1.

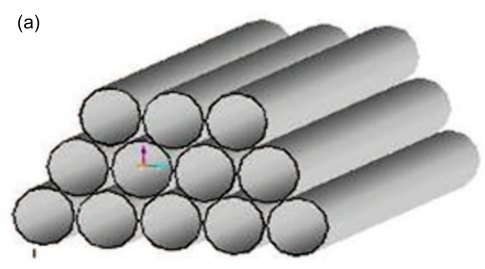

(b)
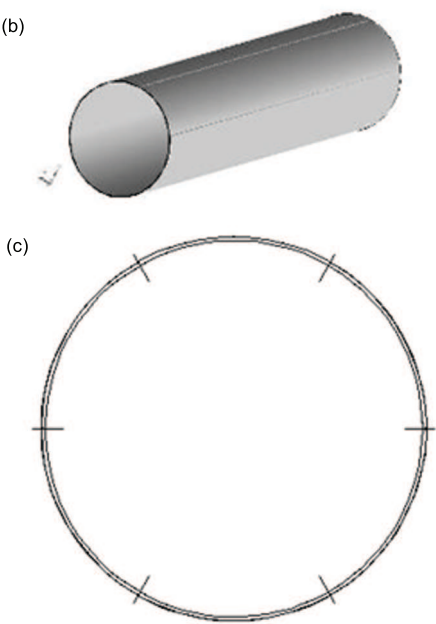

Fig. 1 Sketch of pipe groove corrosion during storage: (a) pipe storage model; (b) corroded groove; (c) groove distribution

The water film on the contacted surface of steel pipe, which gathered from humidity in the air, rain or gel, and the suspended particles in air, and the corrosive composition, such as $\mathrm{SO}_{2}, \mathrm{CO}_{2}, \mathrm{O}_{2}$ and $\mathrm{NaCl}$, in addition to the inhomogeneity of the structure and composition leading to the corrosion cell reaction, caused the corrosion initial from the contacting surface of the between steel pipes, and form the corrosion groove. Generally, the atmospheric corrosion was accompanied with both the oxygen absorption corrosion and the hydrogen evolution corrosion.

The oxygen absorption corrosion reaction is:

$$
\mathrm{Fe}+\mathrm{O}_{2}+2 \mathrm{H}_{2} \mathrm{O}=2 \mathrm{Fe}(\mathrm{OH})_{2}
$$

And, the $\mathrm{Fe}(\mathrm{OH})_{2}$ is going on to be oxidized to $\mathrm{Fe}(\mathrm{OH})_{3}$ :

$$
4 \mathrm{Fe}(\mathrm{OH})_{2}+\mathrm{O}_{2}+2 \mathrm{H}_{2} \mathrm{O}=4 \mathrm{Fe}(\mathrm{OH})_{3}
$$

and $\mathrm{Fe}_{2} \mathrm{O}_{3}$ is formed:

$$
2 \mathrm{Fe}(\mathrm{OH})_{3} \rightarrow \mathrm{Fe}_{2} \mathrm{O}_{3} \cdot n \mathrm{H}_{2} \mathrm{O}+(3-n) \mathrm{H}_{2} \mathrm{O}
$$

At the same time, the reaction of hydrogen evolution corrosion is:

$$
2 \mathrm{H}^{+}+\mathrm{Fe}=\mathrm{H}_{2}+\mathrm{Fe}^{2+}
$$

Normally, the dominant corrosion is the oxygen absorption corrosion, and the secondary corrosion is the hydrogen evolution corrosion.

\section{Material Constants, Parameter and Model}

The stress and strain distribution of the groove corroded pipe were simplified as approximate plane 
strain problem, where the defected pipe has limited length, and the axial stress of pipeline (in longitudinal direction) is constant, and the temperature difference and the weld beam effect on the results were ignored.

The parameters of the pipe material API SPEC $5 \mathrm{~L}$ X70 are as follows: density $7.8 \times 10^{6} \mathrm{~kg} / \mathrm{m}^{3}$, elastic modulus $206 \mathrm{GPa}$, Poisson's ratio 0.3, expansion coefficient $12 \times 10^{-6} /{ }^{\circ} \mathrm{C}$, yield strength $485 \mathrm{MPa}$, ultimate tensile strength $570 \mathrm{MPa}$. The pipe specified size was $\Phi 1016 \mathrm{~mm} \times 21 \mathrm{~mm}$. And the material was isotropic, the effect of the plate rolling and pipe manufacturing on the material properties were ignored. The specified yield strength for X70 is $485 \mathrm{MPa}$ at the strain of $0.5 \%$, and the minimum tensile strength is $570 \mathrm{MPa}$. Due to the fourth strength theory, the material is failed when von Mises equivalent stress or strain is up to the specified yield stress or yield strain. The simulated material X70 grade pipe line steel was considered as elastic plastic, and the stressstrain curve for X70 steel simulated model is shown in Fig. 2.

The corroded groove was simplified, as the most seriously, that it covered 6 corroded grooves, started from $0^{\circ}$ to $360^{\circ}$ at intervals of $60^{\circ}$, and the depth of the corroded grooves were all the same size of $0.125 t$, the length of the corroded grooves were also the same size of pipe length, the direction of grooves was parallel to the pipe axial and from end to end. The bottoms of the corroded grooves were cylinder shaped and the radius of the cylinder was $21 \mathrm{~mm}$. In order to reduce computing work, a quarter section model was taken according to the structure of the pipe symmetry, as shown in Fig. 3. The model was built by ANSYS, and the element type plane 42 was chosen and meshed. The displacement constrain was applied to the horizontal line of the model, $y=0$, as well as the vertical line of the model, $x=0$.

\section{FEM Analysis of the Corrode Groove Defects}

The stress and strain distribution of the defect area near corrosion groove were solved by FEM at the inner pressure of $12 \mathrm{MPa}, 10 \mathrm{MPa}, 8 \mathrm{MPa}, 6 \mathrm{MPa}$,

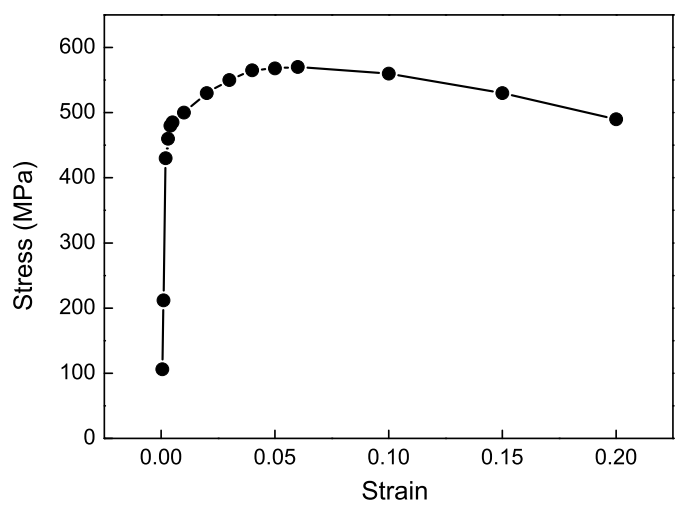

Fig. 2 Stress vs. strain curve for X70 steel model

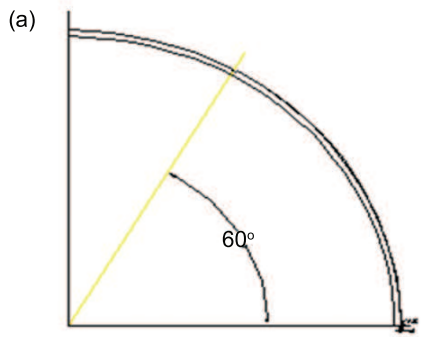

(b)

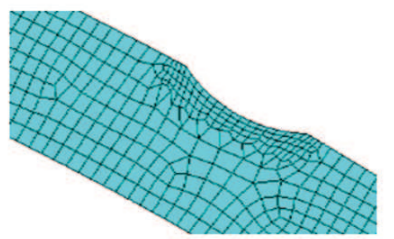

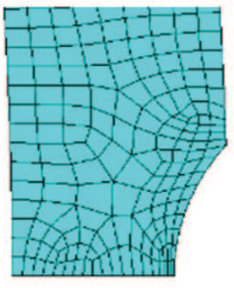

Fig. 3 Simplified corroded groove model: (a) model of pipe; (b) meshed groove at $60^{\circ}$ direction; (c) meshed groove at $0^{\circ}$ direction

$4 \mathrm{MPa}$ and $2 \mathrm{MPa}$, respectively. And the results are shown in Table 1.

Fig. 4 showed that the maximum deformed displacement was increased by the pressure from $2 \mathrm{MPa}$ to $6 \mathrm{MPa}$, and the maximum deformed displacement was turned into the nonlinear relationship with the pressure more than $8 \mathrm{MPa}$.

The maximum deformed displacement was at the horizontal line of the model, that was at the groove at $0^{\circ}$ direction, following at the groove of $60^{\circ}$ direction, and the minimum deformed displacement was at the vertical line of the model, as shown in Fig. 5, displacement of deformed shape and undeformed shape at $8 \mathrm{MPa}$.

The solved stress and strain by FEM at the groove corrode pipe at different pressures were shown in Fig. 6. The 1st principal stress $S_{1}$, von Mises stress $S_{\text {vm }}$ and stress intensity $S_{\text {int }}$ were in good linear relationship with the internal pressure increases from $2 \mathrm{MPa}$ to $6 \mathrm{MPa}$, and the both the $S_{1}$ and $S_{\text {int }}$ were in the same value and higher than the $S_{\mathrm{vm}}$. When came to the pressure above $6 \mathrm{MPa}$, all of the stresses of the corrode groove were felt in the nonlinear model, and the higher the pressure, the more difference among the $S_{1}, S_{\text {int }}$, and $S_{\mathrm{vm}}$, and in the trend of $S_{1}>S_{\text {int }}>S_{\mathrm{vm}}$.

Meanwhile, shown in Fig. 6b, the 1st principal total mechanical strain $S_{\mathrm{n}, 1}$, von Mises total mechanical strain $S_{\mathrm{n}}, v_{\mathrm{m}}$, total mechanical strain intensity $S_{\mathrm{n}, \text { int }}$ were increased as the pressure from $2 \mathrm{MPa}$ to $6 \mathrm{MPa}$, the $S_{\mathrm{n}, 1}$ and $S_{\mathrm{n}, \mathrm{vm}}$ was in the same level, and little less than the $S_{\mathrm{n}, \mathrm{int}}$.

When the pressure was higher than $6 \mathrm{MPa}$, all of the strains were in nonlinear relationship against the pressure, and when the inner pressure was up to $12 \mathrm{MPa}$, all of the strains were greater than $0.5 \%$, began to yield.

Contoured von Mises stress and von Mises strain of groove corrosion defect $(d=0.125 t, P=8 \mathrm{MPa})$ at 
Table 1 Maximum stress and strain of the groove corrode pipe

\begin{tabular}{ccccccccc}
\hline No. & $\begin{array}{c}P \\
(\mathrm{MPa})\end{array}$ & $\begin{array}{c}D_{\max } \\
(\mathrm{mm})\end{array}$ & $\begin{array}{c}S_{1} \\
(\mathrm{MPa})\end{array}$ & $\begin{array}{c}S_{\mathrm{vm}} \\
(\mathrm{MPa})\end{array}$ & $\begin{array}{c}S_{\mathrm{int}} \\
(\mathrm{MPa})\end{array}$ & $\begin{array}{c}S_{\mathrm{n}, 1} \\
\left(10^{-3}\right)\end{array}$ & $\begin{array}{c}S_{\mathrm{n}, \mathrm{vm}} \\
\left(10^{-3}\right)\end{array}$ & $\begin{array}{c}S_{\mathrm{n}, \text { int }} \\
\left(10^{-3}\right)\end{array}$ \\
\hline 1 & 12 & 1.28 & 601 & 488 & 561 & 5.59 & 5.91 & 9.65 \\
2 & 10 & 0.982 & 541 & 471 & 538 & 3.73 & 3.81 & 6.03 \\
3 & 8 & 0.739 & 497 & 426 & 483 & 2.62 & 2.60 & 3.97 \\
4 & 6 & 0.549 & 428 & 380 & 428 & 1.86 & 1.81 & 2.65 \\
5 & 4 & 0.355 & 285 & 254 & 285 & 1.24 & 1.21 & 1.77 \\
6 & 2 & 0.153 & 142.5 & 127 & 142 & 0.62 & 0.60 & 0.88 \\
\hline
\end{tabular}

Note: $P$, pressure; $D_{\max }$, the maximum deformed displacement; $S_{1}, 1$ st principal stress; $S_{\mathrm{vm}}$, von Mises stress; $S_{\text {int }}$, stress intensity; $S_{\mathrm{n}, 1}, 1$ st principal total mechanical strain; $S_{\mathrm{n}, \mathrm{vm}}$, von Mises total mechanical strain; $S_{\mathrm{n}, \text { int }}$, total mechanical strain intensity

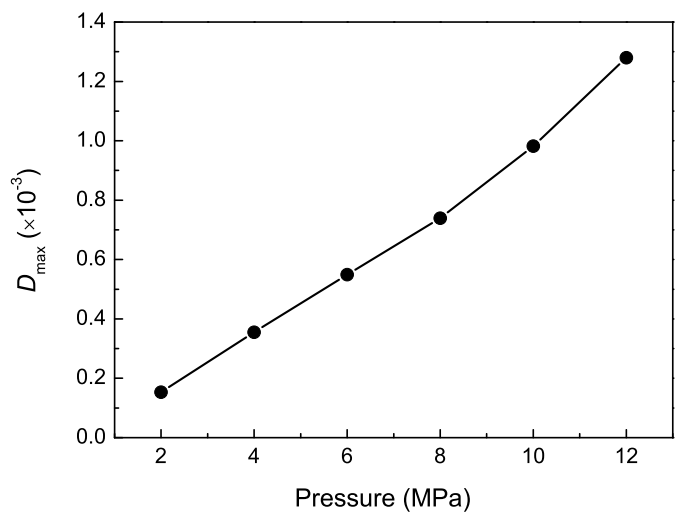

Fig. 4 Variation of the maximum deformed displacement with different pressures of $12 \mathrm{MPa}, 10 \mathrm{MPa}$, $8 \mathrm{MPa}, 6 \mathrm{MPa}, 4 \mathrm{MPa}$ and $2 \mathrm{MPa}$

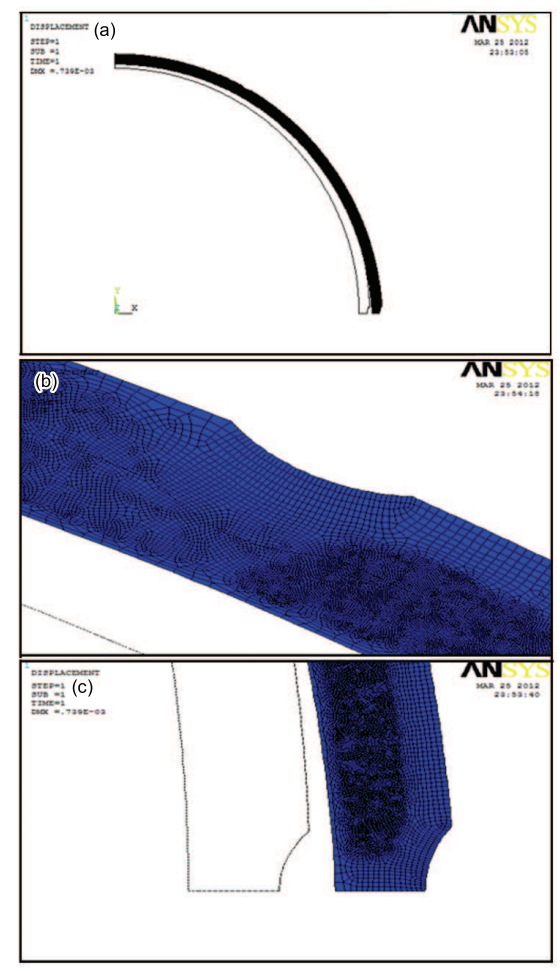

Fig. 5 Displacement of deformed shape and undeformed shape $(P=8 \mathrm{MPa})$ : (a) whole model; (b) groove at $60^{\circ}$ direction; (c) groove at $0^{\circ}$ direction
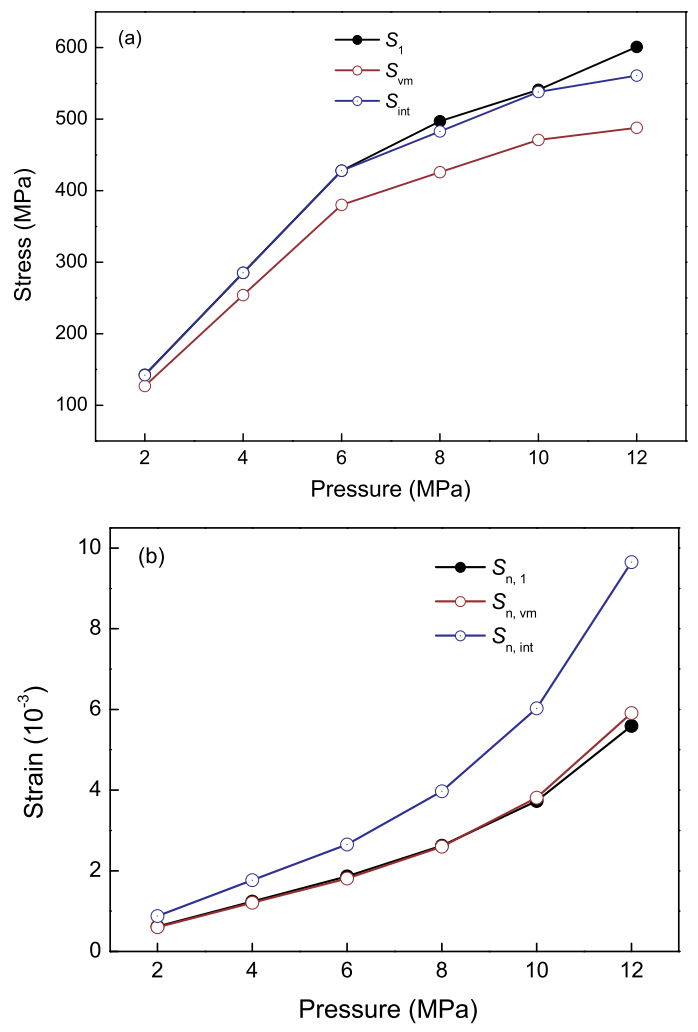

Fig. 6 Stress (a) and strain (b) of the groove corrode pipe at different pressures

$0^{\circ}$ on the $x$ axis direction were much greater than that at $60^{\circ}$ direction, as shown in Fig. 7 and Fig. 8, respectively, and the maximum local equivalent stress and strain were located at the bottom of the groove corrosion defects at $0^{\circ}$ direction, the maximum equivalent stress was $426 \mathrm{MPa}$ and the maximum equivalent strain was $0.26 \%$ at the inner pressure of $8 \mathrm{MPa}$.

Contoured von Mises stress of groove corrosion defect $(d=0.125 t)$ at $0^{\circ}$ on the $x$ axis direction of different inner pressures $4 \mathrm{MPa}, 6 \mathrm{MPa}, 8 \mathrm{MPa}$ and $10 \mathrm{MPa}$ are shown in Fig. 9. It showed that the maximum local equivalent stress was located at the bottom of the corrosion defects groove at $0^{\circ}$ direction, and increased with the inner pressure, were $254 \mathrm{MPa}$, $380 \mathrm{MPa}, 426 \mathrm{MPa}$ and $471 \mathrm{MPa}$, respectively. 


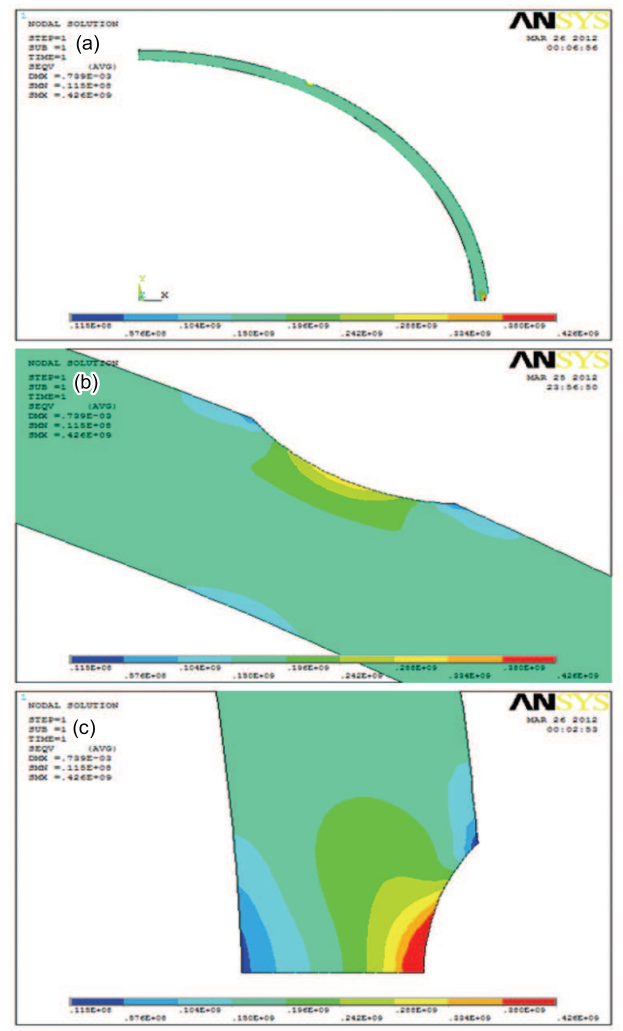

Fig. 7 Contoured von Mises Stress of groove corrosion defect $(d=0.125 t, P=8 \mathrm{MPa})$ : (a) whole model; (b) groove at $60^{\circ}$ direction; (c) groove at $0^{\circ}$ direction
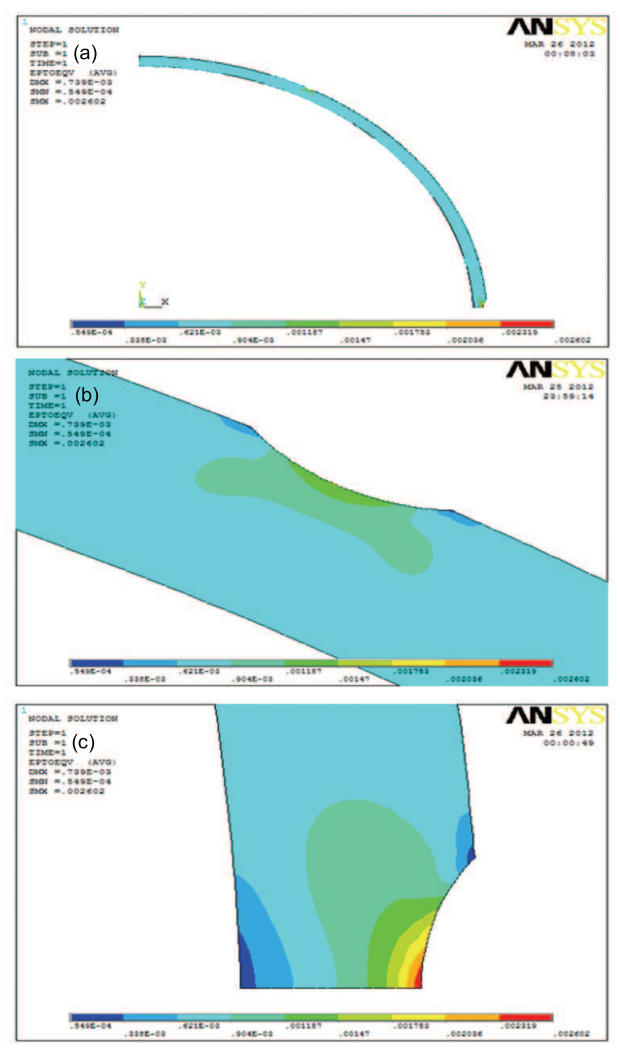

Fig. 8 Contoured von Mises strain of groove corrosion defect $(d=0.125 t, P=8 \mathrm{MPa})$ : (a) whole model; (b) groove at $60^{\circ}$ direction; (c) groove at $0^{\circ}$ direction

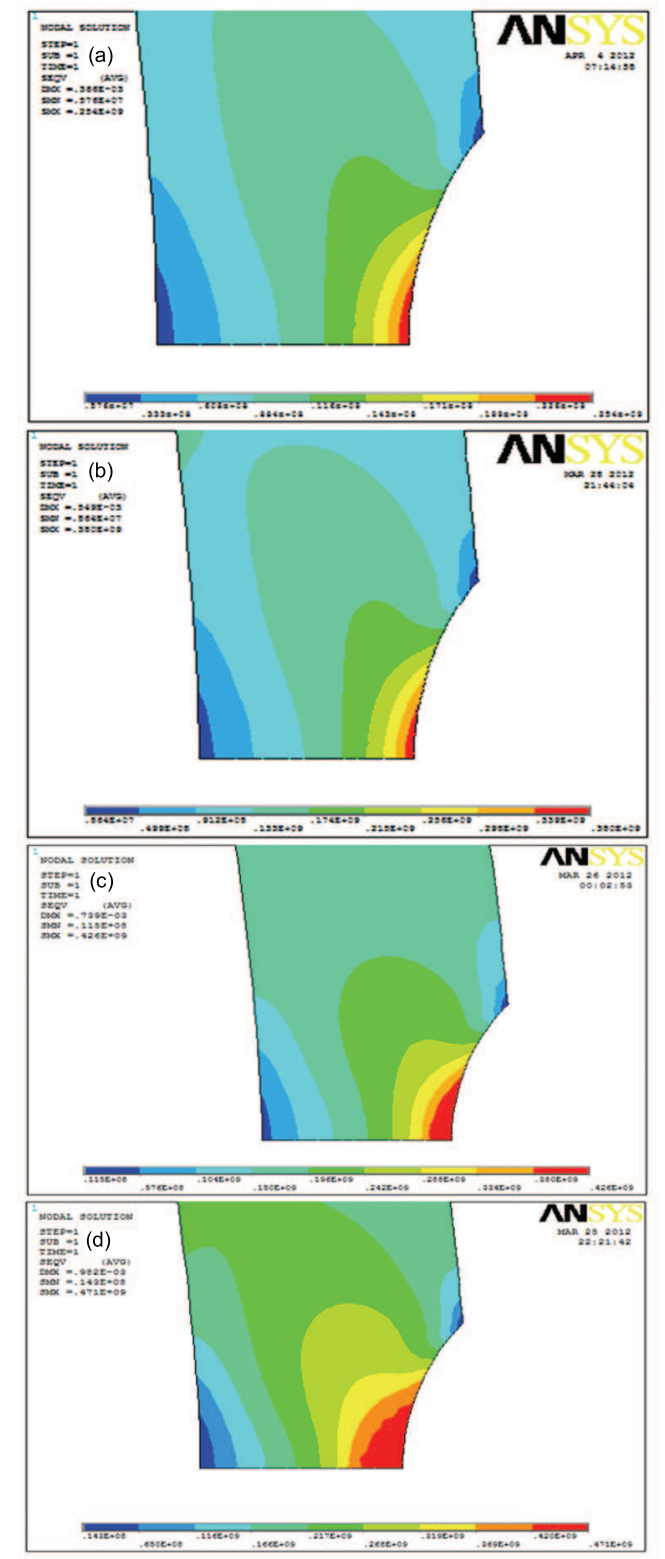

Fig. 9 Contoured von Mises stress of groove corrosion defect $(d=0.125 t)$ : (a) $P=4 \mathrm{MPa}$; (b) $P=6 \mathrm{MPa}$; (c) $P=8 \mathrm{MPa}$; (d) $P=10 \mathrm{MPa}$

Besides, the area of the maximum von Mises stress under the contoured line grew with the inner pressure, which would result in the stress concentration and the failure of the defect bottom.

\section{Residual Strength of Groove Corrosion Defects Pipeline}

\subsection{Stress concentration coefficient model}

Firstly the stress concentration coefficient model of pipe $\Phi 1016 \mathrm{~mm} \times 21 \mathrm{~mm}$ X70API SPEC 5L with the groove corrosion defect of depth $d=0.125 t$, cylinder shaped of radius of $21 \mathrm{~mm}$, should be solved by FEM and theoretical method.

Stress concentration coefficient could be theoretically calculated according to the FEM solution results 
under different inner pressures:

$$
\beta=S_{\mathrm{vm}, \max } / S
$$

where $S_{\mathrm{vm}, \max }$ is the maximum equivalent stress of the corrosion defects groove, solved by FEM; $S$ is the average stress without the defect, calculated according the following formula:

$$
S=\operatorname{Pr} / t
$$

where $r$ is specified outside radius of the pipe.

Similarly, the Stress concentration coefficient based on the strain could be solved according to the formula:

$$
\beta^{\prime}=S_{\mathrm{n}, \mathrm{vm}} / \mu
$$

where $S_{\mathrm{n}, \mathrm{vm}}$ is von Mises total mechanical strain; $\mu$ is the average strain without any defect, $\mu=\sigma / E$ ( $\sigma$ the average stress without the defect, $\sigma=S ; E=$ $206 \mathrm{GPa}$ is the elastic modulus). The results of stress concentration coefficient are shown in Table 2 .

The von Mises stress and strain results of FEM under different inner pressures are shown in Fig. 10. As results above mentioned, the von Mises stress and strain were in nonlinear with the inner pressure from $8 \mathrm{MPa}$ to $12 \mathrm{MPa}$, and when came to the $12 \mathrm{MPa}$, both the von Mises stress (488 $\mathrm{MPa}$ ) and strain $(0.59 \%)$ turned into the yield status.

Theoretically, stress concentration coefficient was only related to the material properties and the defect shape, and would not change as the inner pressure. But the stress concentration coefficient varied under the pressure of $8 \mathrm{MPa}$ to $12 \mathrm{MPa}$ (Fig. 11), which showed that the material properties had been changed from $8 \mathrm{MPa}$.

To sum up, as the stress concentration coefficients calculated under the pressures of $2 \mathrm{MPa}, 4 \mathrm{MPa}$ and $6 \mathrm{MPa}$, the pipe body including the defect area was in the elastic status. The concentration coefficients based on the von Mises stress of FEM were 2.62, 2.625 and 2.62 , respectively, and mean values were 2.62 , as well as $2.57,2.58$ and 2.57 , respectively, mean value 2.57 of that based on von Mises strain.

So the averaged concentration coefficient of that based on the von Mises stress and based on the von
Mises strain was the 2.60. That is, the stress concentration coefficient of the groove corrosion defect of depth $d=0.125 t$, cylinder shaped with radius of $21 \mathrm{~mm}$ should be 2.60 , which could be used for the residual strength solving.

\subsection{Residual strength solved base on theoretical method}

The residual strength of the groove corrosion defect was depended on design coefficient, material structure coefficient, stress concentration coefficient and material yield strength. The wall thickness of the steel pipe was designed as the following formula according to the GB 50251-2003 (Code for design of gas transmission pipeline engineering):

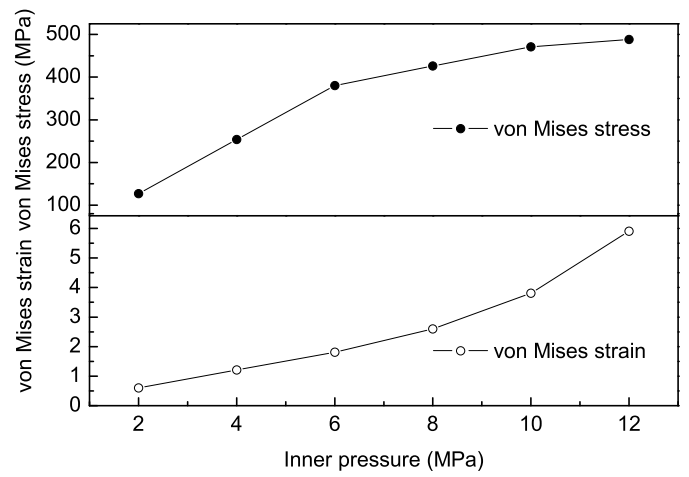

Fig. 10 von Mises stress and strain of FEM

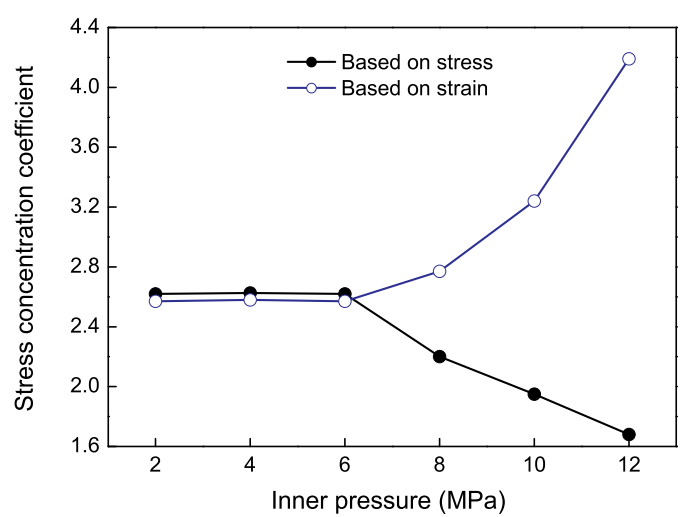

\begin{tabular}{|c|c|c|c|c|c|c|c|}
\hline No. & $\begin{array}{c}P \\
(\mathrm{MPa})\end{array}$ & $\begin{array}{c}S \\
(\mathrm{MPa})\end{array}$ & $\begin{array}{c}\mu \\
\left(10^{-3}\right)\end{array}$ & $\begin{array}{c}S_{\mathrm{vm}} \\
(\mathrm{MPa})\end{array}$ & $\begin{array}{l}S_{\mathrm{n}, \mathrm{vm}} \\
\left(10^{-3}\right)\end{array}$ & $\beta$ & $\beta^{\prime}$ \\
\hline 1. & 12 & 290 & 1.41 & 488 & 5.91 & 1.68 & 4.19 \\
\hline 2. & 10 & 242 & 1.17 & 471 & 3.81 & 1.95 & 3.24 \\
\hline 3. & 8 & 194 & 0.94 & 426 & 2.60 & 2.20 & 2.77 \\
\hline 4. & 6 & 145 & 0.70 & 380 & 1.81 & 2.62 & 2.57 \\
\hline 5. & 4 & 96.8 & 0.47 & 254 & 1.21 & 2.625 & 2.58 \\
\hline 6. & 2 & 48.4 & 0.235 & 126.8 & 0.60 & 2.62 & 2.57 \\
\hline
\end{tabular}

Fig. 11 Calculated stress concentration coefficient

Table 2 Results of stress concentration coefficient 


$$
\delta=P_{\mathrm{des}} r /\left(\sigma_{\mathrm{s}} \psi k t\right)
$$

where $\delta$ is designed wall thickness; $P_{\text {des }}$ is designed transmission pressure; $\sigma_{\mathrm{s}}$ is the specified minimum yield stress; $k$ is strength design factor; $\psi$ is weld bead factor; $t$ is temperature reduced factor.

So the residual strength $\sigma_{\mathrm{r}}$ was defined as follows:

$$
\sigma_{\mathrm{r}}=\psi k t \sigma_{\mathrm{s}} / \beta
$$

where $\sigma_{\mathrm{r}}$ is the residual strength; $k$ is strength design factor, $k=0.72 ; \psi$ is weld bead factor, $\psi=1.0 ; t$ is temperature reduced factor, when temperature $T \leq$ $120{ }^{\circ} \mathrm{C}, t=1.0 ; \sigma_{\mathrm{s}}$ is the specified minimum yield stress, $\sigma_{\mathrm{s}}=485 \mathrm{MPa} ; \beta$ is stress concentration coefficient, 2.60. So that, the residual strength of groove corroded pipe with depth of $0.125 t$ was calculated as $134 \mathrm{MPa}$.

While the limited operation pressure $P_{\mathrm{o}}$ was

$$
P_{\mathrm{o}}=2 \sigma_{\mathrm{r}} \delta / D
$$

And the limited operation pressure of groove corroded pipe with depth of $0.125 t$ was calculated as $5.55 \mathrm{MPa}$.

\subsection{Residual strength solved base on FEM}

The von Mises stress and strain curve on the bottom element of the groove defect under inner pressure $2 \mathrm{MPa}$, and increased by $2 \mathrm{MPa}$ (Fig. 12), which showed that the von Mises stress vs. strain curve on the micro element was similar to that of material in tensile test.

When the von Mises stress came to the yield point $485 \mathrm{MPa}$, the inner pressure could be read as 11.20 $\mathrm{MPa}$, as shown in Fig. 13. When take the design factor into account, the residual strength, as well as the hoop stress of rest of the wall thickness should be: $\sigma_{\mathrm{r}}=t_{\min } / t \sigma_{\mathrm{s}}=424 \mathrm{MPa}\left(\sigma_{\mathrm{s}}=485 \mathrm{MPa}\right)$

So that, the residual strength was $424 \mathrm{MPa}$, and the limit operate pressure 15.3 MPa could be calculated according to the formula $P=2 \sigma_{\mathrm{r}} t_{\mathrm{min}} / D$ for the groove corrosion defect, with depth of $0.125 t$ and cylinder shaped of radius $21 \mathrm{~mm}$.

Similarly the von Mises strain curve of groove corrosion defect with depth of $0.125 t$ at different operate pressure from $2 \mathrm{MPa}$ to $12 \mathrm{MPa}$ are plotted in

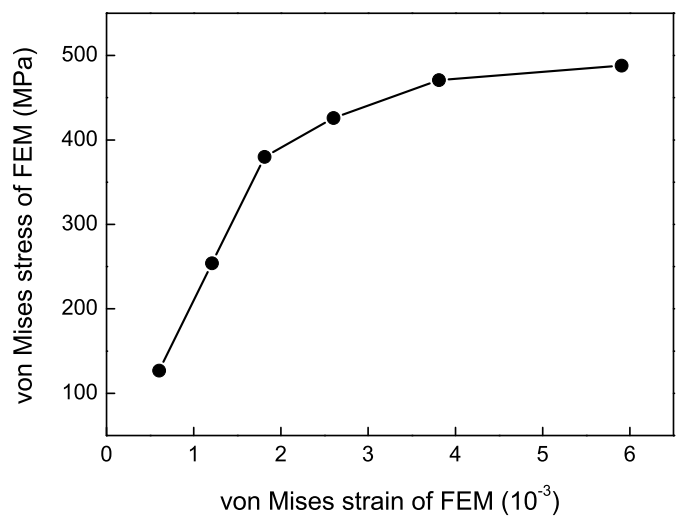

Fig. 12 Stress-strain curve based on FEM $(d=0.125 t)$
Fig. 14, which showed that the von Mises strain was elastic to the inner pressure below $6 \mathrm{MPa}$, and inelastic to the pressure above $6 \mathrm{MPa}$, same as to the von Mises stress.

And the limit operate pressure of pipeline could be read as $11.16 \mathrm{MPa}$ from Fig. 14 when the strain came to the yield point $0.5 \%$, and the residual stress of the rest wall thickness could be calculated as $337 \mathrm{MPa}$.

\subsection{Residual strength solved base on ASME B31G}

The residual strength base on ASME B31G-2009 was calculated as the Level 2, at the given conditions: $r=508 \mathrm{~mm} ; t=21 \mathrm{~mm}$; X70, API SPEC $5 \mathrm{~L}$ steel grade; $\sigma_{\mathrm{s}}=485 \mathrm{MPa}$; specified minimum tensile strength $\sigma=570 \mathrm{MPa} ; d=2.625 \mathrm{~mm}, d / t=0.125 ; L$, the length of the defect, $12000 \mathrm{~mm}$; $A$, the corroded area in longitudinal, $A=d \times L ; A_{0}$, area without corrosion, $A_{0}=t \times L, A / A_{0}=d / t=0.125$.

The flow stress $S_{\text {flow }}$ of X70 was solved according to ASME B31G-2009:

$$
S_{\text {flow }}=\left(\sigma_{\mathrm{s}}+\sigma\right) / 2=527.5 \mathrm{MPa}
$$

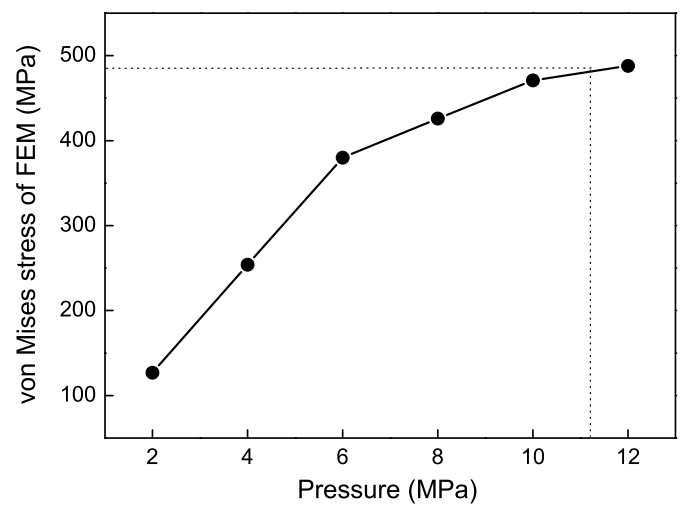

Fig. 13 Solved residual strength based on von Mises stress of FEM $(d=0.125 t)$

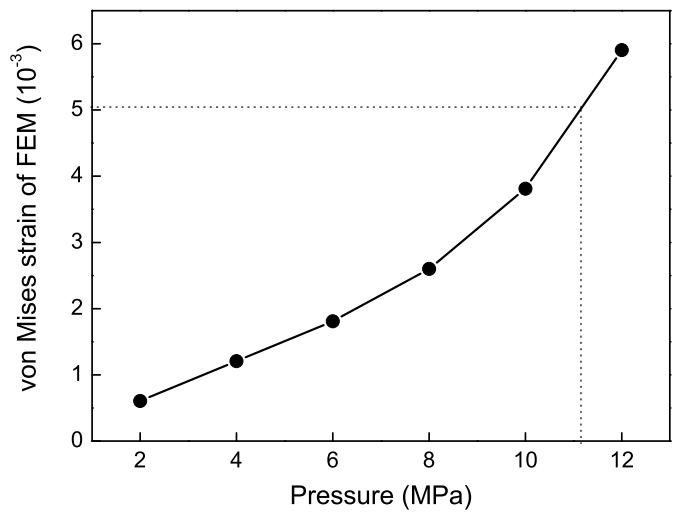

Fig. 14 Solved residual strength based on von Mises strain of FEM $(d=0.125 t)$ 
And assumed that the pipe was under the only inner pressure and in the limited length, and the axial stress was ignored, in this way, the failure stress $S_{\mathrm{F}}$ also the residual strength was shown as the formula:

$$
S_{\mathrm{F}}=S_{\text {flow }}\left[\frac{1-A / A_{0}}{1-\left(A / A_{0}\right) / M}\right]
$$

where $M=0.032 z+3.3$, for this defect $M=5.929$; $z=L^{2} /(2 r t)$, for this defect $z=82.15 ; S_{\mathrm{F}}=471.5 \mathrm{MPa}$.

According to the following formula:

$$
\begin{gathered}
P_{\mathrm{F}}=F_{\mathrm{s}} t_{\min } / r \\
P_{\mathrm{s}}=P_{\mathrm{F}} / F_{\mathrm{s}}
\end{gathered}
$$

where $F_{\mathrm{s}}=1.39$ is the safe factor; $F_{\mathrm{des}}=0.72$, design factor; $t_{\mathrm{min}}$, the minimum wall thickness.

The failure pressure $P_{\mathrm{F}}$, also the limit operate pressure, was 17.05 MPa.

\subsection{Residual strength solved base on DNV-RP-F101}

The residual strength base on DNV-RP-F101 (2004) was calculated as the single defect and only at the inner pressure and the same given conditions of 5.4. The safety class is assumed to be normal. The inspection accuracy quoted by the inspection tool provider is that the defect depth will be reported with $\mathrm{a} \pm 10 \%$ tolerance. This sizing accuracy is quoted with a confidence level of $80 \%$.

Allowable corroded pipe pressure of a single longitudinal corrosion defect under internal pressure loading $P_{\text {corro }}$ :

$$
P_{\text {corro }}=0.74 \frac{2 t \sigma}{(2 r-t)} \frac{\left(1-1.28(d / t)^{*}\right)}{\left(1-\frac{1.28(d / t)^{*}}{Q}\right)}
$$

where:

$$
Q=\sqrt{1+0.31\left(\frac{l}{\sqrt{2 r t}}\right)^{2}}=45.75
$$

where $(d / t)^{*}=d / t+\varepsilon d \times S t d[d / t]=0.33 ; S t d[d / t]$, the standard deviation, $0.08 ; \varepsilon_{\mathrm{d}}$, factor for defining a fractile value for the corrosion depth, $1.0 ; \gamma_{\mathrm{m}}$, partial safety factor for longitudinal corrosion model prediction, $0.74 ; \gamma_{\mathrm{d}}$, partial safety factor for corrosion depth, 1.28 .

We could get $P_{\text {corro }}$ as $13.2 \mathrm{MPa}$, also the limit operate pressure. Meanwhile, the residual stress of the pipeline with the corrosion groove defect was calculated as $398 \mathrm{MPa}$.

\subsection{Laboratory verification of specimen with simulated}

defects by tensile test

\subsubsection{Materials}

The test materials were cut from the longitudinal seam submerged arc welding pipe made from J-C-O-E forming process according to the manufacturing specifications API SPEC 5L $\mathrm{L}^{[1]}$. The pipe with the size of $\Phi 1016 \mathrm{~mm} \times 21 \mathrm{~mm}$, steel grade of X70 PSL2, was full lengthily cold expanded at the expansion rate of $0.8 \%$.

The composition of the pipe materials belong to the classic C-Mn steel and in accord with the specifications API SPEC 5L, as shown in Table 3.

The test coupon specimens were cut from the pipe body and $180^{\circ}$ to the weld beam by flame cutting. The tensile specimens were machined to the rectangular section, with width of $38.1 \mathrm{~mm}$ and gauge of $50 \mathrm{~mm}$, after leveling. The tensile tests were carried out according to the ASTM A370 at room temperature. The tensile properties of pipe body of $\Phi 1016 \mathrm{~mm} \times 21 \mathrm{~mm}$ X70 LSAW pipe are showed in Table 4, the stress strain curve are plotted in Fig. 15. The yield strength is $551 \mathrm{MPa}$, the ultimate tensile

Table 3 Chemical analysis results of tested X70 pipeline steel (wt.\%)

\begin{tabular}{cccccccccc}
\hline & $\mathrm{C}$ & $\mathrm{Si}$ & $\mathrm{Mn}$ & $\mathrm{P}$ & $\mathrm{S}$ & $\mathrm{Cr}$ & $\mathrm{Mo}$ & $\mathrm{Ni}$ & $\mathrm{Nb}$ \\
\hline Pipe body & 0.052 & 0.17 & 1.58 & 0.008 & 0.0014 & 0.021 & 0.21 & 0.005 & 0.053 \\
API 5L & 0.12 & 0.45 & 1.70 & 0.025 & 0.015 & 0.50 & 0.50 & 0.50 & 0.08 \\
& $\mathrm{~V}$ & $\mathrm{Ti}$ & $\mathrm{Cu}$ & $\mathrm{B}$ & $\mathrm{Al}$ & $\mathrm{Ni}+\mathrm{Cr}+\mathrm{Cu}$ & $\mathrm{V}+\mathrm{Nb}+\mathrm{Ti}$ & $C_{\text {eq }}$ & $P_{\mathrm{cm}}$ \\
Pipe body & 0.006 & 0.016 & 0.03 & $<0.0001$ & 0.031 & 0.06 & 0.08 & 0.37 & 0.15 \\
API 5L & 0.06 & 0.025 & 0.50 & 0.004 & 0.06 & 0.50 & 0.15 & 0.43 & 0.25 \\
\hline
\end{tabular}

Note: (1) $C_{\text {eq }}=\mathrm{C}+\mathrm{Mn} / 6+(\mathrm{Mo}+\mathrm{Cr}+\mathrm{V}) / 5+(\mathrm{Ni}+\mathrm{Cu}) / 15$;

(2) $P_{\mathrm{cm}}=\mathrm{C}+\mathrm{Si} / 30+(\mathrm{Mn}+\mathrm{Cu}+\mathrm{Cr}) / 20+\mathrm{Mo} / 15+\mathrm{Ni} / 60+\mathrm{V} / 10+5 \mathrm{~B}$

Table 4 Tensile property of $\Phi 1016 \mathrm{~mm} \times 21 \mathrm{~mm}$ X70 LSAW pipe

\begin{tabular}{ccccc}
\hline Item & $R_{\mathrm{t} 0.5}(\mathrm{MPa})$ & $R_{\mathrm{m}}(\mathrm{MPa})$ & $R_{\mathrm{t} 0.5} / R_{m}$ & Elongation rate $(\%)$ \\
\hline X70 & 551 & 658 & 0.84 & 43.5 \\
API 5L & $485-620$ & $\geq 570$ & $\leq 0.90$ & $\geq 22$ \\
\hline
\end{tabular}

Note: $R_{\mathrm{t} 0.5}$, yield strength; $R_{\mathrm{m}}$, ultimate tensile strength 
strength $658 \mathrm{MPa}$, the rate of yield strength to ultimate tensile strength 0.84 , and the elongation rate $43.5 \%$, they are all in accord with the specification API SPEC 5L.

\subsubsection{Simulated defects specimen}

The specimens with the simulated groove corrosion defects, were machined from the normal rectangular section specimen by numerical control milling machine. The groove defects were cutting to cylindrical bottom by the milling cutter with diameter of $40 \mathrm{~mm}$, and the groove depth $d$ was set to $2.625 \mathrm{~mm}$, namely $0.125 t$.

The specimen drawing and picture were shown in Fig. 16. It was assumed that the pipeline was infinite long, and the axial stress in the pipe body was ignored. So that the pipeline body was only bare in the circumferential direction tensile stress, namely, normal hoop stress when the pipe was under the inner pressure.

Therefore, it was reasonable and feasible to analysis the residual stress and the limit operate pressure of the corrosion pipeline with groove defects by using the strip specimen of transverse direction (perpendicular to the pipe axis direction) as tensile test.

\subsubsection{Test results}

The 3 simulated specimens tensile test results, as shown in Table 5, were very close to each other, and the averaged results of the 3 specimens were: yield strength $529 \mathrm{MPa}$, ultimate tensile strength $601 \mathrm{MPa}$, and the elongation rate $33.8 \%$. The results were obviously declined to those of full section specimen. The yield strength and ultimate tensile strength of the groove defect specimens were declined by $4.0 \%$ and $8.7 \%$, respectively, and the elongation rate declined by $33.8 \%$.

The comparison between stress strain curve of defect depth $d=0$ and $d=0.125 t$ was made, as plotted in Fig. 17, which showed that the stress strain curve of the defect specimen was a little higher than that of the specimen without defect during the elastic stage, and begin to get down the stress strain curve of the specimen free of defect during the plastic stage.

The sample containing groove defect had a better resistance to the deformation than that of the full section sample, which was resulted from the bottom of the groove defect turned into the yield state firstly. The average local extension rate of the 3 grooved specimens reaches to $84.12 \%$.

The actual tensile properties have enough strength allowance compared the minimum requirement of the specification API SPEC 5L. In order to compare to the FEM result accurately, the material safety coefficient $M_{\mathrm{S}}$ was introduced to get rid of the spare strength: $M_{\mathrm{s}}=\left[R_{\mathrm{t} 0.5} / 485, R_{\mathrm{m}} / 570\right]_{\max }$

So as: $M_{\mathrm{s}}=1.154$. So the practical tensile results of the groove defects specimen could be revised as the following: $R_{\mathrm{ys}}=R_{\mathrm{t} 0.5}^{\prime} / M_{\mathrm{s}}=458 \mathrm{MPa}$; $R_{\mathrm{ms}}=R_{\mathrm{m}}^{\prime} / M_{\mathrm{s}}=520 \mathrm{MPa}$.

The material strength loss coefficient $K_{\mathrm{s}}$ was defined as the follows to analysis the strength loss of groove defect.

$$
K_{\mathrm{s}}=\left[K_{\mathrm{y}}, K_{\mathrm{m}}\right]_{\max }
$$

where $K_{\mathrm{y}}=\left(R_{\mathrm{t} 0.5}^{0}-R_{\mathrm{t} 0.5}^{\prime}\right) / R_{\mathrm{t} 0.5}^{0}$

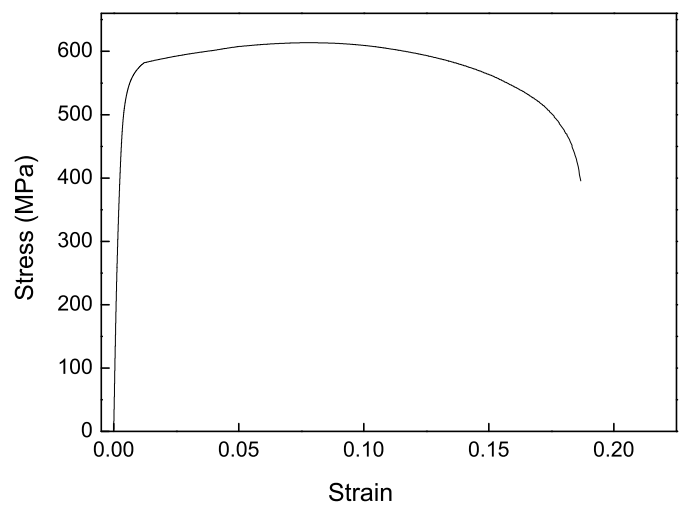

Fig. 15 Tensile stress-strain curve of $\varphi 1016 \mathrm{~mm} \times 21 \mathrm{~mm}$ X70 LSAW pipe body
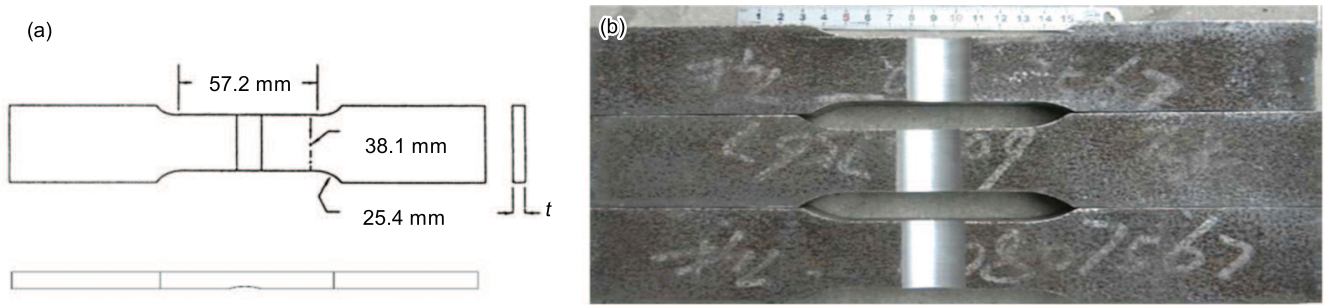

Fig. 16 Groove specimens for tensile test: (a) drawing, (b) photos

Table 5 Tensile test results of specimen with corroded groove defect $(d=0.125 t)$

\begin{tabular}{ccccccc}
\hline Item & No. & Depth $(\mathrm{mm})$ & $R_{\mathrm{t} 0.5}(\mathrm{MPa})$ & $R_{\mathrm{m}}(\mathrm{MPa})$ & $R_{\mathrm{t} 0.5} / R_{\mathrm{m}}$ & Elongation rate (\%) \\
\hline$d=0.125 t$ & 1 & 2.24 & 519 & 597 & 0.87 & 34.0 \\
& 2 & 2.12 & 535 & 609 & 0.88 & 33.5 \\
& 3 & 3.34 & 532 & 597 & 0.89 & 34.0 \\
& Average & 2.57 & 529 & 601 & 0.88 & 33.8 \\
$d=0$ & $/$ & 0 & 551 & 658 & 0.84 & 43.5 \\
\hline
\end{tabular}




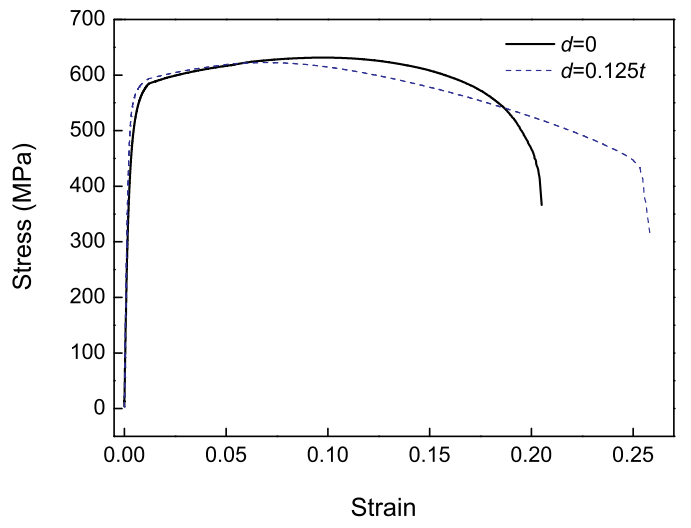

Fig. 17 Stress vs. strain curves of specimen with and without defect

$$
R_{\mathrm{m}}=\left(R_{\mathrm{m}}^{0}-R_{\mathrm{m}}^{\prime}\right) / R_{\mathrm{m}}^{0}
$$

$R_{\mathrm{t} 0.5}^{0}, R_{\mathrm{m}}^{0}$, the actual yield strength and ultimate tensile strength of the full section specimen; $R_{\mathrm{t} 0.5}^{\prime}, R_{\mathrm{m}}^{\prime}$, the actual yield strength and ultimate tensile strength of groove defect specimen; According to the test results of Table 5 , the material strength loss coefficient $K_{\mathrm{s}}$ was calculated as $10.5 \%$.

So the equivalent yield strength and ultimate tensile strength of groove defect specimen $R_{\mathrm{t} 0.5}^{\mathrm{e}}, R_{\mathrm{m}}^{\mathrm{e}}$ was shown as follows:

$$
\begin{gathered}
R_{\mathrm{t} 0.5}^{\mathrm{e}}=R_{\mathrm{ys}}\left(1-K_{\mathrm{s}}\right)=410 \mathrm{MPa} \\
R_{\mathrm{m}}^{\mathrm{e}}=R_{\mathrm{ms}}\left(1-K_{\mathrm{s}}\right)=468 \mathrm{MPa}
\end{gathered}
$$

So the residual strength $\sigma_{\mathrm{r}}$ of the groove defect specimen with depth of $d=0.125 t$, should be the equivalent yield strength $410 \mathrm{MPa}$.

And the limit operate strength was calculated as the $P=14.8 \mathrm{MPa}$, from the following formula.

$$
P=2 \sigma_{\mathrm{r}} t_{\min } / D
$$

So, the residual strength $\sigma_{\mathrm{r}}$ of the groove corrosion defect specimen with depth of $d=0.125 t$ was tested and equivalent as $410 \mathrm{MPa}$, the limit operate strength was 14.8 MPa.

\subsection{Discussion and Analysis}

The residual strength and limit operate pressure of different methods are shown in Table 6 , in which the minimum residual strength is $186 \mathrm{MPa}$ by theoretical method, the maximum residual strength 471 MPa by ASME B31G method. While the residual strength of the FEM is $424 \mathrm{MPa}$, very close to the result of the experiments $410 \mathrm{MPa}$, the absolute error is $14 \mathrm{MPa}$, and the relative error $3.30 \%$. At the same time, the limit operate pressure of the FEM and experiments were 15.34 $\mathrm{MPa}$ and $14.78 \mathrm{MPa}$, respectively, the absolute error is $0.56 \mathrm{MPa}$, and the relative error is $3.65 \%$. Meanwhile, residual strength of DNVRP-F101 is $398 \mathrm{MPa}$, which are similar to the results of the FEM and experiment.
Table 6 Residual strength limit operate pressure and safe operate pressure of different methods (MPa)

\begin{tabular}{cccc}
\hline Method & $S_{\mathrm{r}}$ & $P_{\mathrm{l}}$ & $P_{\mathrm{s}}$ \\
\hline Theory method & 186 & 7.64 & 5.55 \\
FEM based on stress & 424 & 15.34 & 11.04 \\
FEM based on strain & 337 & 11.16 & 8.04 \\
ASME B31G & 471.5 & 17.05 & 12.28 \\
DNV-RP-F101 & 398 & 13.18 & 9.49 \\
Experiment & 410 & 14.78 & 10.64 \\
\hline
\end{tabular}

Note: $S_{\mathrm{r}}$, residual strength; $P_{1}$, limit operate pressure; $P_{\mathrm{s}}$, safe operate pressure, $P_{\mathrm{s}}$ $=0.72 P_{1}$

The minimum yield strength and the stress concentration effect were employed to calculate the residual stress of the corrosion defect line pipe in the theory method, which lead to the conservative results.

While the failure criteria of ASME B $31 \mathrm{G}$ was based on the flow stress $S_{\text {flow }} 527 \mathrm{MPa}$, it was the average of the specified minimum yield strength and specified minimum tensile strength, by which the residual stress of the corrosion defect line pipe was solved as 471.5 MPa. Obviously, the result of the ASME B $31 \mathrm{G}$ was at a higher risk because of introducing the specified minimum tensile strength during the calculating the flow stress.

And the limit operate pressure $P_{1}$ of $13.18 \mathrm{MPa}$ was solved on the foundation of the specified minimum tensile strength $\sigma$ and of the influence of the pipeline corrosion defects size according to DNV-RPF101. So that the residual stress of the corrosion defect line pipe was calculated as the $398 \mathrm{MPa}$, which was less by $12 \mathrm{MPa}$ to the result of the experiment.

In conclusion, the finite element method could be adopted to solve the residual strength of pipe with cylindrical bottom corrosion groove defect with full length long and $0.125 t$ deep, by which the results were very close to that of experiments.

\section{Conclusions}

(1) The finite element method could be adopted to solve the residual strength of pipe with cylindrical bottom corrosion groove defect.

(2) Corrode groove defect on outside of steel pipe during storage should belong to the atmospheric corrosion, and accompanied with the dominant oxygen absorption corrosion and the secondary hydrogen evolution corrosion.

(3) The stress concentration coefficient of the groove corrosion defect of depth $d=0.125 t$, cylinder shaped with radius of $21 \mathrm{~mm}$ is 2.60 .

(4) The maximum local equivalent stress located at the bottom of the groove at $0^{\circ}$ direction, increased with the inner pressure and firstly get into the failure point. 
(5) For the groove corrosion defect with the depth of $0.125 t$, cylinder shaped of radius $21 \mathrm{~mm}$, the residual strength is $424 \mathrm{MPa}$ and the limit operate pressure 15.34 MPa, which were solved by FEM with more accuracy.

\section{Acknowledgements}

This work was financially supported by the National Natural Science Foundation of China (Nos. 51101127 and 51171154) and Soar Star of Northwestern Polytechnical University (2011) and Fundamental Research Foundation of Northwestern Polytechnical University (No. JC201213).

\section{REFERENCES}

[1] H. Adib-Ramezani, J. Jeong and G. Pluvinage, Int. J.
Pressure Vessels Piping 83 (2006) 420.

[2] C.I. Anghel, Int. J. Pressure Vessels Piping 86 (2009) 403.

[3] X.Y. Yang, R.Y. He and C.Z. Liu, Pipe Technol. Equipment 1 (2009) 47. (in Chinese)

[4] M.H. Meliani, Y.G. Matvienko and G. Pluvinage, Eng. Failure Anal. 18 (2011) 271.

[5] B.C. Rollins, G.T. Quickel, J.A. Beavers and T.A. Bubenik. NACE Corrosion Conference, Nashville, Tennessee, USA, 2007.

[6] D. Rivas, F. Caleyo, A. Valor and J.M. Hallen, Corros. Sci. 50 (2008) 3193.

[7] F. Caleyo, J.C. Velázquez, A. Valor and J.M. Hallen, Corros. Sci. 51 (2009) 1925.

[8] M.S.G. Chiodo and C. Ruggieri, Int. J. Pressure Vessels Piping 86 (2009) 164.

[9] X.K. Zhu and B.N. Leis, Int. J. Pressure Vessels Piping 83 (2006) 663.

[10] H. Moustabchir, Z. Azari, S. Hariri and I. Dmytrakh, J. Eng. Failure Anal. 17 (2010) 506. 